\title{
VERLEIHUNG DES BERUFSTITELS „PROFESSOR“ AN HANS-JOACHIM ALSCHER UND MARKUS STUMPF
}

Bereits im September 2020 wurde wHR Mag. Hans-Joachim Alscher, dem Bibliotheksdirektor der Niederösterreichischen Landesbibliothek der Berufstitel „Professor" verliehen.

Im April 2021 wurde diese Ehre dann auch Mag. Markus Stumpf, MSc, dem Leiter der Fachbereichsbibliothek Zeitgeschichte und der NS-Provenienzforschung der Universitätsbibliothek der Universität Wien, für seine wissenschaftlichen Verdienste als Bibliothekar, Provenienzforscher und Zeithistoriker zuteil.

DOI: https://doi.org/10.31263/voebm.v74i1.6191

(c) Redaktion der Mitteilungen der VÖB

Dieses Werk ist - exkl. einzelner Logos und Abbildungen - lizenziert unter einer Creative-Commons-Lizenz Namensnennung 4.0 International-Lizenz 